We should like to thank Dr. Srečko Rainer and Dr. Ellen Grant for examining the endometrial biopsy specimens and Dr. Cizelj for assessing the results of the postcoital tests. Miss Rosemary Emerson assisted with the statistical analysis.

We should also like to acknowledge the financial assistance given by the Population Council. British Drug Houses Ltd., Schering Chemicals Ltd., Syntex Pharmaceuticals Ltd., and John Wyeth and Brother Ltd. kindly provided the contraceptive tablets.

\section{REFERENCES}

Chiazze, L., Brayer, F. T., Macisco, J. J., Parker, M. P., and Duffy, B. J. (1968). Fournal of the American Medical Association, 203 377.

Connell, E. B. (1967). In Advances in Planned Parenthood, edited by A. J. Sobrero and S. Lewit, p. 74. New York, Excerpta Medica.
Foss, G. L., Svendsen, E. K., Fotherby, K., and Richards, D. J. (1968). British Medical fournal, 4, 489.

Grant, E. C. G. (1964). Fournal of Reproduction and Fertility, 8, 275.

Grant, E. C. G. (1967). Fournal of Obstetrics and Gynaecology of the British Commonwealth, 74, 908.

Martinez-Manautou, J., Giner-Velasquez, J., Aznar-Ranios, R., LozanoBalderas, M., and Rudel, W. H. (1967a). In Proceedings of the 8th International Conference of the International Planned Parenthood Federation. London, I.P.P.F.

Martinez-Manautou, J., et al. (1967b). British Medical fournal, 2, 730.

Rudel, H. W., Martinez-Manautou, J., and Maqueo-Topete, M. (1965). Fertility and Sterility, 16, 158.

Sujan, S., Danezis, J., and Sobrero, A. J. (1963). Fournal of Reproduction and Fertility, 6, 87.

Treloar, A. E., Boynton, R. E., Behn, B. G., and Brown, B. W. (1967) International fournal of Fertility, 12, 77 .

Zañartu, J., Rodriguez-Moore, G., Pupkin, M., Salas, O., and Guerrero, R. (1968). British Medical fournal, 2, 263.

\title{
Reproductive Potential of Patients Treated by Maintenance Haemodialysis
}

\author{
M. ELSTEIN,* M.B., CH.B., M.R.C.o.G. ; E. K. M. SMITH,† M.D., B.SC., M.R.C.P. ; J. R. CURTIS, † M.D., M.R.C.P.
}

British Medical fournal, 1969, 2, 734-736

Summary: Three of the wives of 25 men undergoing $\checkmark$ maintenance haemodialysis for terminal renal failure became pregnant. This suggests that fertility is not necessarily impaired in these patients and that contraceptive methods should be used by women patients at risk.

\section{Introduction}

It is commonly stated that patients with severe chronic renal failure are either sterile or strikingly subfertile. Amenorrhoea often occurs in women, and in men impotence is a common complaint (Schreiner and Maher, 1965). While the abnormal chemistry of the uraemic state may have some specific effects on ovulation and spermatogenesis, patients with severe renal failure are suffering from a chronic and debilitating disease, whose effects on reproductive processes may be entirely nonspecific.

Until recent times such patients seldom survived very long; hence the emotional and social consequences of their infertility were not great. The development of facilities for maintenance haemodialysis, however, has offered such patients an opportunity to return to a more useful life and often to productive work (Curtis et al., 1969). In this situation the question of sexual potency and fertility becomes much more relevant, both to the patient, who regards it is an important part of his return to a more normal life, and to the physician, who has to handle the pregnancies that may arise. It is clearly no longer justifiable to assume that the infertility and impotence of the uraemic state continue when maintenance dialysis is begun, for there have been occasional reports of male patients successfully impregnating their wives. There is, however, no record of a successful pregnancy occurring in a woman treated by longterm dialysis. This paper reports three instances of pregnancy occurring in the spouses of men who have terminal renal failure, and who have been satisfactorily maintained by haemo-

* Lecturer in Obstetrics and Gynaecology.

+ Senior Lecturer in Medicine.

Charing Cross Hospital Medical School, London W.6. dialysis. In addition, an investigation of the sexual activity of 35 patients on maintenance haemodialysis indicates that a significant number of them are able to enjoy an active sexual life.

\section{The Patients}

Since March 196441 patients have been treated by maintenance haemodialysis at Fulham Hospital; of these, 35 were available for the present study. Twelve treat themselves in the home, while the remainder are dialysed in hospital; all have at least 28 hours of dialysis each week by means of a Kiil dialyser and a single-pass warm dialysate system (Curtis et al., 1969). Access to the blood stream is by a standard TeflonSilastic arteriovenous shunt. Among the patients reviewed there were 25 men and 10 women.

In six of the women normal periods returned after the start of dialysis, and in four instances an $x$-ray menopause has been induced because of the exacerbation of their anaemia due to prolonged and heavy periods. None of our female patients has become pregnant; two have been seen for disturbances of sexual function because they both experienced a diminution of libido after radiotherapy. They were treated with vaginal oestrogen cream (dienoestrol) and given advice on sexual techniques. They are both now achieving satisfactory relations, with orgasm-an improvement on their performance before they became ill.

Pregnancy has, however, occurred in the wives of three male patients ; all three have successfully delivered normal babies.

\section{Case 1}

This patient was first seen at the age of 22 with acute glomerulonephritis, and over the next two years had five episodes of haematuria; he then remained well until he developed nocturia and thirst at the age of 30 and was found, a year later, to be hypertensive, anaemic, and to have a blood urea of $300 \mathrm{mg} . / 100 \mathrm{ml}$. He was started on maintenance haemodialysis at this time, and his renal failure has been well controlled, though his first year of treatment was marred by the development of progressive deafness, 
possibly associated with the use of ototoxic antibiotics. In spite of this he has gone back to full-time work as a director of a small company.

Before the terminal phase of his illness he had led an active sexual life, having satisfactory intercourse two or three times per week, and had a son when he was 29 ; the year preceding this his wife had had a spontaneous early abortion. In the three months before starting maintenance haemodialysis his sexual activity ceased, but after dialysis was established his libido returned. $\mathrm{He}$ and his wife became extremely anxious to have another child. In view of his presumed subfertility (poor semen analysis and haematospermia) he and his wife were seen for this. She was given ethinyloestradiol $0.05 \mathrm{mg}$. at mid-cycle (day 10 to 14 ) on four occasions in order to enhance the function of her cervical mucus. Postcoital tests showed only the occasional motile sperm, and the question of artificial insemination by donor was seriously considered at the request of the patient and his wife. At this point, however, the wife became pregnant. The pregnancy was uncomplicated, resulting in the spontaneous delivery of a normal girl weighing $8 \mathrm{lb} .6 \mathrm{oz}$. $(3,800 \mathrm{~g}$.) The parents consented to studies of the blood groups of the infant and both parents, which were carried out by Dr. R. A. Zeitlin and supported the view that the patient was the child's true father.

\section{Case 2}

At the age of 27 this patient was noted to have proteinuria at a routine medical examination; at the age of 31 he began to suffer from severe headache and was found to be hypertensive and to have a blood urea of $150 \mathrm{mg} . / 100 \mathrm{ml}$. In spite of good control of his blood pressure he developed increasing impairment of renal function and was started on maintenance haemodialysis when the plasma creatinine had reached $15 \mathrm{mg} . / 100 \mathrm{ml}$

Before his final illness he had fathered two children, both as the result of planned pregnancies; he had had regular sexual intercourse, about twice a week, using a sheath as a contraceptive. During the six months before starting dialysis, however, he had had no sexual intercourse because he was "too tired to bother." Soon after starting treatment his libido returned and he resumed sexual activity much as before his illness. He took no contraceptive measures because he thought that " patients on dialysis were sterile." His management by haemodialysis was very satisfactory and he was able to return to full-time work as a bank official.

In January of 1968 his wife became pregnant. Her pregnancy was uneventful and concluded with the spontaneous delivery of a normal girl, weighing $7 \mathrm{lb} .6 \mathrm{oz}$. $(3,345 \mathrm{~g}$.). Both the patient and his wife were willing to allow blood group studies to be done, and these supported the view that the patient was the true father of the infant.

\section{Case 3}

This patient had a trace of proteinuria at the age of 5 . When aged 17 he had transient haematuria, which recurred when he was 21 , and he began to have headaches. He also became pale. Vomiting began and he was found to have a blood urea of $298 \mathrm{mg}$./ $100 \mathrm{ml}$. After several peritoneal dialyses he was started on maintenance haemodialysis at the age of 23 .

He was married at the age of 19 , and up to the time of his illness he had had intercourse about once a week or once a fortnight. A child was born in the first year of the marriage. When he was ill sexual intercourse continued, but only on a very few occasions, and at no time were any contraceptive measures taken. After the start of dialysis he began to feel better, the only abnormality being the transient appearance of gynaecomastia during the first six months of treatment.

He continued to have intercourse, with no precautions, as frequently as before his illness. Seven months after he started dialysis his wife became pregnant, and after an entirely normal course a girl weighing $7 \mathrm{lb}$. $10 \mathrm{oz}$. (3,460 g.) was born. Again parentage was supported by blood group studies.

\section{Semen Analysis}

Analysis of semen from these three patients was carried out and the results showed that in all of them subfertility might have been expected (Table I).
TABlE I.-Semen Analysis Carried Out on the Three Patients Whose

\begin{tabular}{|c|c|c|c|c|}
\hline & & Case 1 & Case 2 & Case 3 \\
\hline Volume .. & . & $5.0 \mathrm{ml}$. blood- & $1.3 \mathrm{ml}$. & $0.5 \mathrm{ml}$ \\
\hline $\begin{array}{l}\text { Density .. } \\
\text { Motility . }\end{array}$ & $\begin{array}{l}\ldots \\
\cdots\end{array}$ & $\begin{array}{l}\text { stained } \\
13 \mathrm{million} / \mathrm{ml} \\
35^{\circ}\end{array}$ & $\begin{array}{l}7.5 \text { million } / \mathrm{ml} \\
73^{\circ} \%\end{array}$ & $\begin{array}{l}5.0 \text { million } / \mathrm{ml} \text {. } \\
\text { No motile forms } \\
\text { seen }\end{array}$ \\
\hline $\begin{array}{l}\text { Abnormal forms } \\
\text { Reaction } \\
\text { Viability }\end{array}$ & & $\begin{array}{l}50^{\circ} \\
\text { Alkaline } \\
\text { No motile forms } \\
\text { after } 18 \text { hours at } \\
\text { room temp. }\end{array}$ & $6 \%$ & $4 \%$ \\
\hline
\end{tabular}

\section{Sexual Activity}

Our review of all the patients available for study is detailed in Table II, which indicates that of the 35 only 10 were likely to show their fertility, or lack of it. All were men who were having regular sexual intercourse without any contraceptive precautions, and three of these proved that they are indeed fertile, even though semen analysis was subnormal.

TABLe II.-Fertility Potential in 35 Patients with Renal Failure Treated by Matntenance Haemodialysis

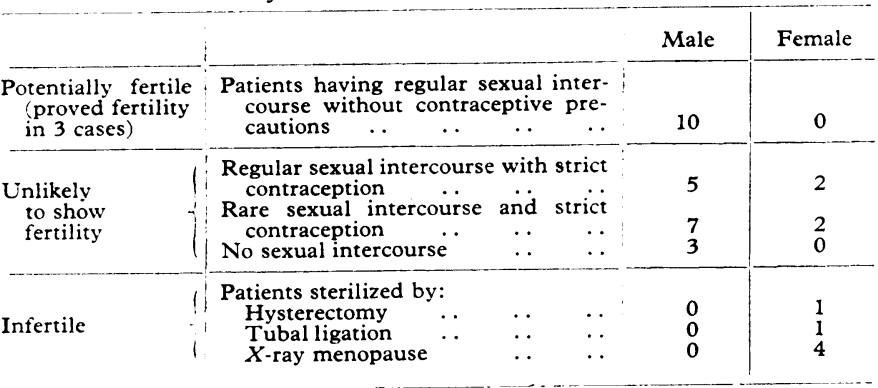

From our discussions with the patients we formed the view that in most cases libido had returned to the level which they had recognized as normal before the period of ill-health, which was due to renal disease and later led to haemodialysis. Some of the women had little interest in sex, but considered this to be unrelated to their physical disease. Where loss of libido had been very obvious before haemodialysis many patients considered it to be due to their being "too ill" or " too tired" or "too preoccupied" to bother ; there seemed to be little evidence that uraemia had any more specific effect than any other serious and terminal chronic illness.

\section{Discussion}

While it is still generally accepted that many women with renal failure are infertile (Oken, 1966) it is by no means certain whether this is due to any specific effects of uraemia per se or merely to the chronic ill-health that accompanies it. Relatively little information is available regarding male patients, but the same rules have usually been thought to apply.

Without any good reason it has of ten been assumed that this subfertile state would continue when the patient was treated by maintenance haemodialysis, though such treatment is known to reverse many of the other complications of the uraemic state. Sokol et al. (1967) noted arrested and abnormal spermatogenesis in five patients dying during the course of repeated dialysis ; however, since these patients died, one might assume that they were not representative of those who survive in reasonable health. Goodey and Kelly (1967) thought that many patients on maintenance dialysis had sexual difficulties, and reported normal sexual activity in only 2 out of 14 patients under their care. Our experience does not agree with this, but like others we had continued to suppose that pregnancy in the wives of our male patients was unlikely to occur. We therefore did not, initially, give any strong advice regarding the need for contraceptive precautions; as a result three unexpected pregnancies 
have occurred. In fact, artificial insemination would have been an unfortunate mistake in the one couple in whom it was considered during their treatment for secondary infertility.

There is clear evidence that apparently complete restoration of reproductive function can occur if chronic renal failure is completely reversed by successful renal transplantation. Hume et al. (1966) described proved fertility in a man and successful pregnancy in a woman, both of whom were being treated with long-term immunosuppressive therapy following renal transplantation. Though maintenance dialysis is only an incomplete substitute for normal renal function, it can be remarkably effective in avoiding or reversing the complications of prolonged uraemia. In men it certainly does not influence fertility; whereas in women the picture is more complicated, since the severe anaemia, which cannot be corrected by dialysis, would make the continuation of a pregnancy hazardous. Nevertheless, women on dialysis may be fertile, and ovulation has occurred in women on such treatment (Goodwin et al., 1968. This matches our own experience in that normal menstruation has returned in several patients soon after starting maintenance dialysis, and this has led us to advise contraceptive precautions in those of our female patients who might be at risk. Because of the possible side-effects of oral contraceptives, which include a risk of clotting the arteriovenous shunt and poor control of hypertension, we have recommended the use of mechanical methods of contraception such as a sheath or diaphragm with a spermicidal jelly.

Among our 10 male patients having sexual intercourse with no contraceptive precautions the three resulting pregnancies are perhaps a better index of fertility than the results of semen analysis. In a healthy population over a similar time period one would expect to see about twice the fertility rate we saw in these 10 patients (Tietze, 1962 ; Barton, 1968).

We wish to thank Dr. C. P. Farthing and Dr. N. Peele for carrying out the semen analyses and Professor H. E. de Wardener and Professor N. Morris for their help in reviewing the manuscript. Dr. R. A. Zeitlin kindly carried out the blood group studies in the South London Blood Transfusion Centre, Sutton, Surrey.

REFERENCES

Barton, M. (1968). Fournal of Reproduction and Fertility, 16, 327.

Curtis, J. R., et al. (1969). Quarterly foumal of Medicine, 38, 49.

Goodey, J., and Kelly, J. (1967). Lancet, 2, 147.

Goodwin, N. J., Valenti, C., Hall, J. E., and Friedman, E. A. (1968). American fournal of Obstetrics and Gynecology, 100, 528.

Hume, D. M., et al. (1966). Annals of Surgery, 164, 352.

Oken D E (1966). American fournal of Obstetrics and Gynecology,

94, 1023.
Schreiner, G. E., and Maher, J. F. (1965). Annals of Internal Medicine, 62, 551 .

Sokol, 6 . (1967). Transactions. American Society for Artificial Internal Organs, 13, 51

Tietze, C. (1962). Population Studies, 16, 31.

\title{
Effect of Diazepam on Awareness during Caesarean Section Under General Anaesthesia
}

\author{
DAVID J. TURNER, $†$ M.B., F.F.A. R.C.S., D.A. ; JAMES WILSON,* M.B., F.F.A. R.C.S., D.OBST.R.C.O.G.
}

\begin{abstract}
Summary: The use of diazepam for premedication $S$ before elective caesarean section increased the incidence of unpleasant recall postoperatively, compared with atropine in a previous study. This finding suggests that diazepam is unsuitable for this type of anaesthesia.
\end{abstract}

\section{Introduction}

In our previous investigation of awareness during caesarean section under general anaesthesia (Wilson and Turner, 1969) it was shown that the administration of a narcotic within six hours of operation significantly reduced the incidence of unpleasant recall (recall of awareness during operation, of pain, or of unpleasant dreaming during anaesthesia). As it would appear to be unjustifiable to give a narcotic premedicant routinely before elective section we had hoped to show a similar effect (reduction in unpleasant recall) with the benzdiazepine group of tranquillizing drugs.

\section{Method}

During the period of inquiry all patients who were to undergo elective caesarean sections were premedicated with $10 \mathrm{mg}$. of diazepam by mouth on the night before operation and $10 \mathrm{mg}$. intramuscularly together with $0.6 \mathrm{mg}$. of atropine one hour preoperatively.

Patients requiring emergency section were used as the comparative group; the criterion for this group being operation during labour because of foetal or maternal distress. Some of these patients had received narcotics within six hours of operation, this being dictated purely by the requirements to produce pain relief during labour; the others had received only $0.6 \mathrm{mg}$. of atropine intramuscularly.

The patient population and the methods of assessment and inquiry were as used in our previous series (Wilson and Turner, 1969) apart from minor alterations in the questionary indicated by our previous results.

\section{Results}

Of the total 82 patients studied, the 17 who had received a narcotic within six hours of operation had no unpleasant recall of facts from the operation or of pain, but two of them could recall unpleasant dreams (Table I). This incidence of unpleasant recall, while higher than the figure in our previous series, must be considered in the light of the small number of patients and therefore the lesser likelihood of normal distribution in the current series compared with the previous one. Moreover, of the 39 who received atropine only preoperatively three $(7.6 \%)$ had definite recall of awareness during some part of the anaesthetic, while one patient-though having some recollection of intubation-was unable to recall anything else apart from an unpleasant dream. This total of four $(10 \cdot 2 \%)$

* Lecturer.

† Senior Registrar.

tenior Registrar. ary, Edinburgh 3 . 